\title{
Clinical Pharmacist Intervention and the Proportion of Diabetes Patients Attaining Prevention Objectives in a Multispecialty Medical Group
}

\author{
Rosalyn S. Padiyara, PharmD, CDE; Jennifer J. D'Souza, PharmD, CDE; and Rami S. Rihani, PharmD
}

\begin{abstract}
BACKGROUND: Clinical practice recommendations from American Diabetes Association (ADA) include specific prevention goals intended to reduce the risk of diabetic complications. The Healthy People 2010 (HP2010) initiative, updated to Healthy People 2020, proposes similar objectives for improvement of clinical measures and outcomes in patients with diabetes. Clinical pharmacists are gaining an increasing role in providing diabetes management services, including collaborative practice in medical groups.

OBJECTIVE: To compare the rates of attainment of diabetes prevention goals described by the ADA 2009 guidelines and the HP2010 initiative for patients receiving clinical pharmacist interventions in a collaborative practice diabetes clinic versus patients receiving usual care.

METHODS: The setting is a primary care clinic affiliated with a 140-physician multispecialty medical group in the upper Midwest. Diabetes patients were identified from electronic medical records by ICD-9-CM diagnosis codes 250.00 through $\mathbf{2 5 0 . 9 9}$ for dates of service in the 12-month period from January 1, 2007, through December 31, 2007. Study subjects had to be aged 18 years or older and have at least 2 visits to a primary care physician (PCP) or the pharmacist-managed diabetes clinic during 2007. Descriptive statistics and chi-square analysis were utilized.
\end{abstract}

RESULTS: 0 f 7,068 patients at least 18 years of age with at least 1 diabetes diagnosis code for a medical encounter in 2007, 1,298 (18.4\%) had a least 1 visit in the pharmacist-managed diabetes clinic, and 321 patients $(4.5 \%)$ had 2 or more visits. These 321 patients were compared with 321 patients stratified by gender and randomly selected from 3,022 patients who had at least 2 visits with a PCP and no visits in the pharmacist-managed diabetes clinic in 2007. Nine of the 14 HP2010 objectives $(64.3 \%)$ were attained in the intervention group compared with 7 of $14(50.0 \%)$ in the usual care group. For patients with hypertension at baseline, $44.6 \%(120 / 269)$ in the intervention group versus $48.0 \%(123 / 256)$ in the usual care group achieved goal blood pressure $(P=0.430)$. The low-density lipoprotein (LDLC) goal ( $<100$ milligrams per deciliter) was achieved in $76.0 \%$ of patients in the intervention group (244/321) versus $59.2 \%(190 / 321)$ in usual care $(P<0.001)$. Fewer patients in the intervention group achieved hemoglobin A1c $<7 \%(50.8 \%, n=163 / 321)$ compared with usual care $(71.0 \%$, $\mathrm{n}=228 / 321, P<0.001)$. The proportions of patients with influenza and pneumococcal vaccinations were higher in the intervention group versus the usual care group for 3 of 4 comparisons by age, but neither group met the target goals.

CONCLUSIONS: Patients who were seen by the clinical pharmacists met more of the preventive care objectives recommended by the ADA 2009 and HP2010 initiatives; however, more patients in usual care met the A1c goal compared with pharmacist-managed patients. The absence of baseline values for A1c, blood pressure, and LDL-C prevented longitudinal assessment of the effects of this clinical pharmacist intervention.

J Manag Care Pharm. 2011;17(6):456-62

Copyright $\odot 2011$, Academy of Managed Care Pharmacy. All rights reserved.
T he published literature shows that when pharmacists are added to the health care team in providing diabetes management, an improvement in glycosylated hemoglobin (Alc) can be seen. ${ }^{1-4}$ Additional targets for diabetes care, such as normalization of blood pressure and reduction in 10-year risk for cardiovascular events according to Framingham risk scores, have also been achieved in studies of pharmacist interventions. ${ }^{1-3,5,6}$ The effects of clinical pharmacist interventions in attainment of preventive goals in diabetes have not been assessed. The standards of medical care in diabetes from the American Diabetes Association (ADA) suggest specific preventive goals to reduce the risk of or slow the progression of complications related to diabetes, including nephropathy, retinopathy, and cardiovascular disease. ${ }^{7,8}$ The 2009 ADA standards of medical care in diabetes proposed the following goals to prevent diabetes-related complications: annual eye and foot exams, annual screening for the presence of urinary microalbumin, low-density lipoprotein cholesterol (LDL-C) $<100$ milligrams per deciliter (mg per dL), blood pressure $<130 / 80$ millimeters mercury $(\mathrm{mm} \mathrm{Hg}$ ), and daily aspirin therapy. ${ }^{7}$ The 2010 and 2011 updates to the ADA standards of medical care in diabetes narrowed the recommended use of aspirin to persons with increased cardiovascular risk, defined as most men aged over 50 years and women aged over 60 years who have at least 1 additional major cardiovascular risk factor (e.g., family history of cardiovascular disease, hypertension, smoking, hyperlipidemia, or albuminuria). ${ }^{9,10}$ The ADA and Centers for Disease Control and Prevention also recommend an annual influenza vaccination for all patients 6 months of age or older and at least 1 lifetime pneumococcal vaccine for patients with diabetes who are at least 2 years of age..$^{10,11}$

The Healthy People 2010 (HP2010) initiative proposed clinical practice recommendations similar to the recommendations issued by the ADA (2009 and 2010). 7,9,12 HP2010 is a national initiative managed by the Office of Disease Prevention and Health Promotion and the U.S. Department of Health and Human Services. The initiative was developed to help increase life expectancy, improve quality of life, and eliminate health disparities of individuals in the United States. ${ }^{12}$ HP2010, superseded by HP2020, ${ }^{13}$ includes specific health objectives 


\section{Clinical Pharmacist Intervention and the Proportion of Diabetes Patients Attaining Prevention Objectives in a Multispecialty Medical Group}

\section{FIGURE 1 Selected Diabetes-Related and Diabetes-Specific HP2010 Objectives}

\begin{tabular}{|c|c|}
\hline Objectives & Target $^{\mathbf{a}}$ \\
\hline $\begin{array}{l}\text { Diabetes-Specific (Objectives } 5 \text { and 12) } \\
\text { - Increase the proportion of persons with diabetes who receive formal diabetes education } \\
\text { - Increase the proportion of adults with diabetes who obtain an annual urinary microalbumin measurement } \\
\text { - Increase the proportion of adults with diabetes who have an A1c measurement at least twice a year } \\
\text { - Increase the proportion of adults with diabetes who have an annual dilated eye examination } \\
\text { - Increase the proportion of adults with diabetes who have at least an annual foot examination } \\
\text { - Increase the proportion of persons with diabetes who have at least an annual dental examination } \\
\text { - Increase the proportion of adults with diabetes who take an aspirin at least } 15 \text { times per month } \\
\text { - Increase the proportion of adults with diabetes who perform self-monitoring of blood glucose (SMBG) at least once daily }\end{array}$ & $\begin{array}{l}60 \% \\
\text { Developmental }^{\mathrm{b}} \\
72 \% \\
76 \% \\
91 \% \\
71 \% \\
30 \% \\
60 \%\end{array}$ \\
\hline $\begin{array}{l}\text { Heart Disease (Objective 12) } \\
\cdot \text { Increase the proportion of persons with coronary heart disease who have their LDL cholesterol treated to a goal } \\
\leq 100 \mathrm{mg} \text { per } \mathrm{dL}\end{array}$ & Developmentale \\
\hline $\begin{array}{l}\text { Chronic Kidney Disease (Objective 4) } \\
\text { - Increase the proportion of persons with type } 1 \text { or type } 2 \text { diabetes and proteinuria who received recommended me } \\
\text { therapy to reduce progression to chronic renal insufficiency. }\end{array}$ & $30 \%$ \\
\hline $\begin{array}{l}\text { Chronic Kidney Disease (Objective } 14 \text { ) } \\
\text { - Influenza and pneumococcal vaccination of high-risk adults } \\
\text { - For noninstitutionalized high-risk adults aged } 65 \text { years or older } \\
\text { - For noninstitutionalized high-risk adults aged } 18-64^{\dagger}\end{array}$ & $\begin{array}{l}90 \% \\
60 \%\end{array}$ \\
\hline $\begin{array}{l}\text { Vutrition (Objective 19) } \\
\text { - Increase the proportion of physician office visits made by patients with a diag } \\
\text { or hyperlipidemia that include counseling or education related to diet and nutr }\end{array}$ & $75 \%$ \\
\hline $\begin{array}{l}\text { Physical Activity (Objective 22) } \\
\text { - Reduce the proportion of adults who engage in no leisure-time physical activity }\end{array}$ & $20 \%$ \\
\hline $\begin{array}{l}\text { Tobacco Use (Objective } 27) \\
\text { - Reduce prevalence of tobacco use among adults-cigarette smoking } \\
\text { - Increase smoking cessation attempts by adult smokers } \\
\end{array}$ & $\begin{array}{l}12 \% \\
75 \% \\
\end{array}$ \\
\hline \multicolumn{2}{|c|}{ 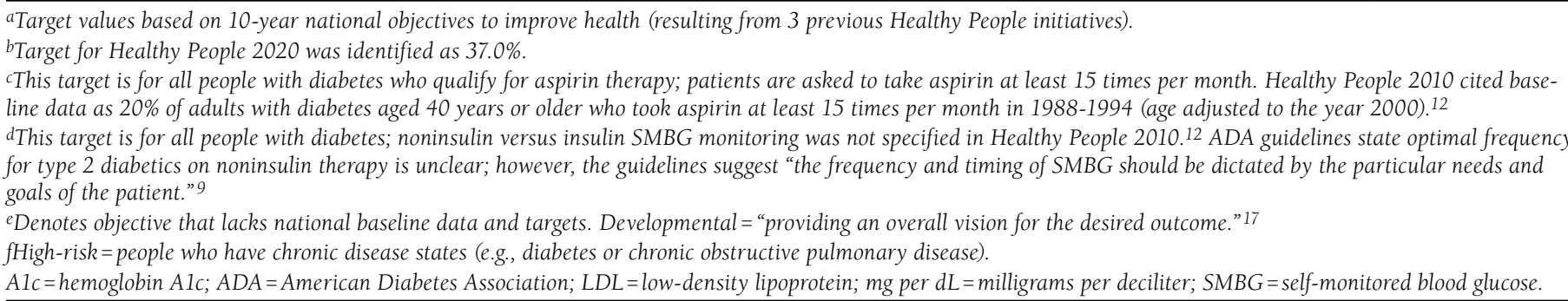 } \\
\hline
\end{tabular}

in 28 different areas of health care, including diabetes and diabetes-related comorbidities. Selected diabetes-specific and diabetes-related HP2010 objectives are shown in Figure 1. Health care professionals serve as important intermediaries to assist patients in accomplishing the ADA and HP2010-2020 preventive care measures. Clinical pharmacists are gaining an increasing role in providing patient care services, specifically in diabetes management. ${ }^{14-16}$

The purpose of this study was to compare the rates of treatment goal achievement for patients receiving clinical pharmacist interventions with patients receiving usual physician care, based on prevention goals described by the ADA clinical practice recommendations and the HP2010 initiative for patients with diabetes mellitus (Figure 2).

\section{Methods}

\section{Setting}

This study was a retrospective review of electronic medical records (EMRs) to assess whether there was a difference in goal achievement for diabetes management for patients enrolled in a pharmacist-managed diabetes clinic versus usual physician care in a primary care medical practice. The primary care clinic provides services to Medicare, managed care, and fee-for-service patients within a multispecialty physician group practice located in the Midwest region. The organization is composed of more than 140 physicians and 600 full-time and 400 part-time support staff who provide care at 11 service locations in a suburban metropolitan area in Illinois. Usual care for patients with diabetes includes the provision of preventive care services and screenings; medication management; education of the patient 


\section{Clinical Pharmacist Intervention and the Proportion of Diabetes Patients Attaining Prevention Objectives in a Multispecialty Medical Group}

\section{FIGURE 2 Preventive Care Measures in the Present Study}

Healthy People 2010 ${ }^{12}$

Proportion of patients receiving an A1c in the 6 months preceding data collection ${ }^{\mathrm{a}}$

Proportion of patients who receive formal diabetes education

Proportion of adults with diabetes who obtain an annual urinary microalbumin measurement

Proportion of adults with diabetes who have an annual dilated eye exam

Proportion of adults with diabetes who have at least an annual foot exam

Proportion of adults with diabetes who take an aspirin at least 15 times per month

Proportion of adults with diabetes who perform SMBG at least once daily

Proportion of patients with diabetes and proteinuria on an ACE inhibitor or ARB

Influenza and pneumococcal vaccination of high-risk adults ${ }^{b}$

For noninstitutionalized high-risk adults aged 65 years or older (obtained at any date)

For noninstitutionalized high-risk adults aged 18-64 years (annual)

Proportion of adults who smoke

Increase smoking cessation attempts by adult smokers

Proportion of patients with a dietician visit in the previous 12 months $^{c}$

Proportion of adults who engage in no leisure-time physical activity

\section{ADA Goals ${ }^{7}$}

Proportion of patients with diabetes and hypertension achieving goal blood pressure $<130 / 80 \mathrm{~mm} \mathrm{Hg}$

Proportion of patients achieving goal LDL-C $<100 \mathrm{mg}$ per $\mathrm{dL}$

Proportion of patients achieving goal A1c $<7 \%$

aThe biannual Alc objective was simplified to evaluate whether an Alc was measured in the 6 months prior to data extraction.

${ }^{b}$ High-risk = people who have chronic disease states (e.g., diabetes or chronic obstructive pulmonary disease).

'The objective of annual physician office counseling on diet was modified to determine whether or not dieticians were used to counsel patients annually.

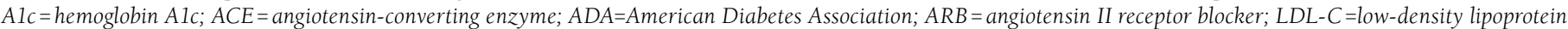
cholesterol; $\mathrm{mg}$ per $\mathrm{dL}=$ milligrams per deciliter; $\mathrm{mm} \mathrm{Hg}=$ millimeters mercury; $S M B G=$ self-monitored blood glucose.

by the primary care physician (PCP), nurse practitioners or physician assistants working under the supervision of the PCP, or nursing staff working directly with the PCP; and referral to other physician specialists (e.g., endocrinology) if deemed appropriate by the PCP.

\section{Description of the Intervention}

Through a collaborative practice agreement, 3 university-affiliated pharmacists educate and directly manage drug therapy and preventive care services for patients diagnosed with diabetes mellitus. Patients can be referred to the pharmacistmanaged diabetes clinic by either physician referral or through an automatic referral process. The automatic referral process allows the pharmacists, via protocol and without a physician referral, to enroll patients into the diabetes clinic who have an Alc of $9 \%$ or higher. There are no formal criteria for physician referral to the pharmacist-managed diabetes clinic, and the physician referrals come from across the continuum-of-care for patients with diabetes (i.e., including those with new diagnoses, long-standing diabetes, and those with controlled to severely uncontrolled diabetes). Reasons for physician referral vary depending on assessments of patients and include those who require medication titration or reconciliation, initiation of insulin, and diabetes education to those needing close monitoring and follow-up. Pharmacists manage these patients per protocol that emphasizes the ADA guidelines. Pharmacists have autonomy in assessing patients, providing disease-state education, reviewing current medication lists, initiating or adjusting medication therapy, ordering laboratory tests, and determining appropriate follow-up. Pharmacists meet with new patients for approximately 45 minutes at the initial visit and returning patients for approximately 30 minutes per visit.

\section{Sample Selection}

For the purposes of this study, a convenience sample of 321 patients with diabetes managed by PCPs (usual care group) were compared with 321 patients enrolled in a pharmacist-managed diabetes clinic (intervention group) between January 1, 2007, and December 31, 2007. Cases in the intervention and usual care groups were pulled from a sample of 7,068 total patients (1,298 intervention and 5,770 usual care, Figure 3). A Crystal Reports database query identified 24,768 encounters that had at least 1 diabetes diagnosis code (International Classification of Diseases, Ninth Revision, Clinical Modification [ICD-9-CM] code range 250.00-250.99) during the 12 months in calendar year 2007 in the primary care departments (internal medicine or family practice). The 7,068 unique patients were divided into those who had previous visits with the pharmacist-managed diabetes clinic $(1,298)$ and those who had no history of visits $(5,770)$ with the pharmacist-managed diabetes clinic. 


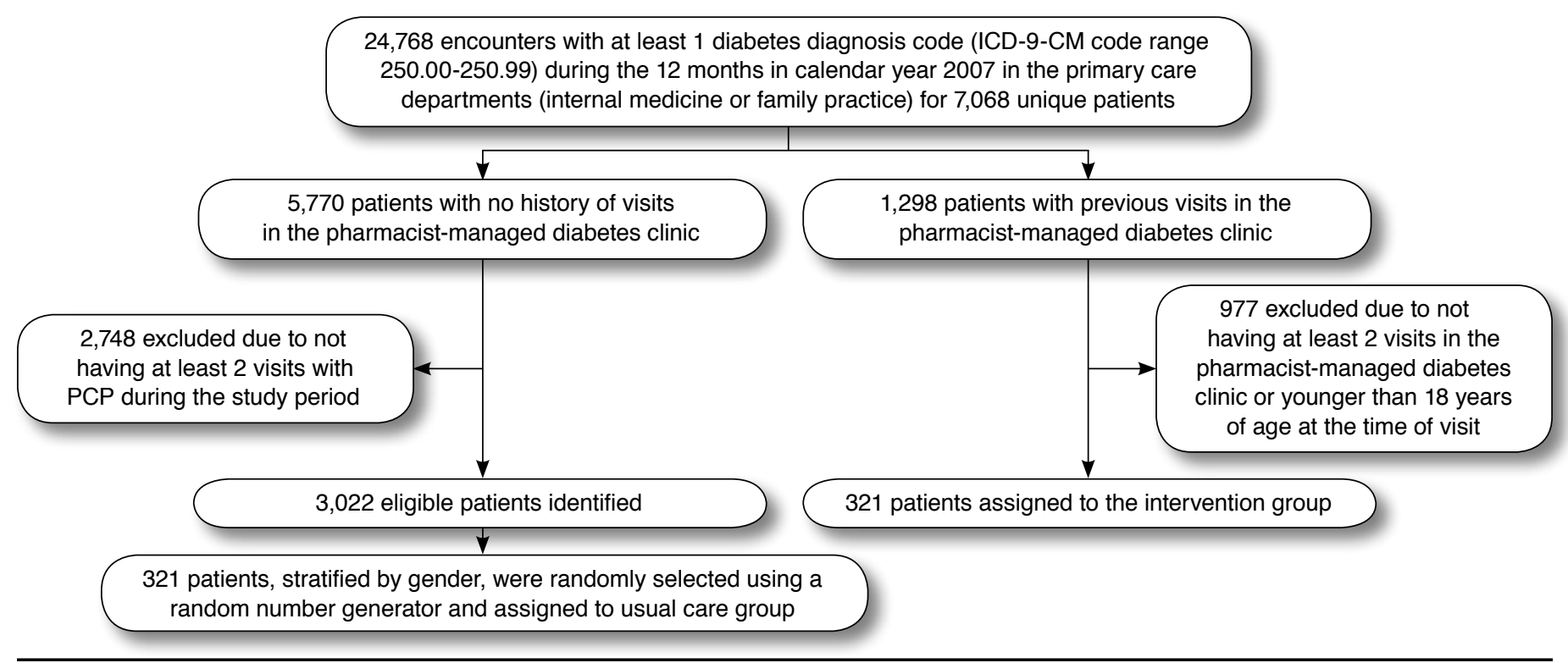

ICD-9-CM = International Classification of Diseases, Ninth Revision, Clinical Modification; $P C P=$ primary care physician.

Of the 1,298 patients with previous visits with the pharmacist-managed diabetes clinic, only 321 patients (150 male, 171 female) were aged 18 years or older and had 2 or more visits within the pharmacist-managed diabetes clinic during the study period. This intervention group was compared with 321 patients who were randomly selected after gender stratification from among 3,022 diabetes patients who had at least 2 medical encounters with a PCP and no interaction with the pharmacistmanaged diabetes clinic in 2007.

The data for general demographics; laboratory values/dates; visit dates (office visits, education visits, dietician visits); vital signs such as blood pressure, vaccinations, medications, eye, and foot examinations; and smoking status/counseling were extracted using Crystal Reports database queries. Other information such as race, physical activity, dentistry visits, and self-monitored blood glucose (SMBG) frequency were extracted through manual chart review of all clinic encounters with dates of service during calendar year 2007. The extracted data were entered manually into a Microsoft Access 2003 Database (Microsoft Inc., Redmond, WA). The manual chart review and manual data entry were completed by a doctor of pharmacy candidate; all Crystal Reports database queries and Microsoft Access 2003 data manipulations were performed by one of the authors (Rihani).

Descriptive statistics and chi-square analysis were used to analyze the results of this study. This study was approved by the Midwestern University Institutional Review Board.

\section{Results}

Six hundred forty-two medical records were reviewed in this study ( $n=321$ for each group). The majority of patients had type 2 diabetes $(n=310$ [96.6\%] in usual care and $n=302$ [94.1\%] in the intervention group), and more than $60 \%$ were Caucasian in both groups ( $n=199$ in usual care and $n=219$ in the intervention group, Table 1).

The review of the ADA clinical measures identified 269 patients in the intervention group and 256 patients in the usual care group who had a diagnosis of hypertension. Of these, $44.6 \%(n=120 / 269)$ in the intervention group and $48.0 \%$ $(n=123 / 256)$ in the usual care group were at goal blood pressure at the most recent measurement $(P=0.430)$. LDL- $C$ goal was achieved in $76.0 \%$ of patients in the intervention group $(n=244 / 321)$ versus 59.2\% $(n=190 / 321)$ in the usual care group $(P<0.001$, Table 2$)$.

The intervention group achieved 9 of the 14 HP2010 objectives (12 objectives in Table 2 and 2 vaccination objectives in Table 3) measured in the present study, compared with 7 of 14 objectives achieved in the usual care group. Neither the usual care group nor the intervention group achieved the influenza and pneumococcal vaccination objectives, but the proportion of patients with vaccinations was higher for the intervention group in 3 of the 4 comparisons by age (Table 3). The intervention group had higher proportions of patients with goal achievement in formal diabetes education, annual urinary 


\section{Clinical Pharmacist Intervention and the Proportion of Diabetes Patients Attaining Prevention Objectives in a Multispecialty Medical Group}

\section{TABLE 1 Patient Characteristics}

\begin{tabular}{|c|c|c|c|}
\hline & $\begin{array}{c}\text { Usual Care } \\
\text { n (\%) }\end{array}$ & $\begin{array}{c}\text { Intervention } \\
\mathrm{n}(\%)\end{array}$ & $P$ Value ${ }^{a}$ \\
\hline Number & 321 & 321 & \\
\hline \multicolumn{4}{|l|}{ Gender } \\
\hline Male & $150 \quad(46.7)$ & $150 \quad(46.7)$ & - \\
\hline Female & $171 \quad(53.3)$ & $171 \quad(53.3)$ & - \\
\hline \multicolumn{4}{|l|}{ Mean [SD] age in years } \\
\hline Male & $63.6[11.9]$ & $61.4[13.5]$ & 0.138 \\
\hline Female & $65.5[14.4]$ & $62.6[14.2]$ & 0.062 \\
\hline Race & & & 0.087 \\
\hline Caucasian & $199 \quad(61.9)$ & $219 \quad(68.2)$ & \\
\hline African American & $(2.8)$ & $(8.1)$ & \\
\hline Hispanic or Latino & $51 \quad(15.9)$ & $(18.4)$ & \\
\hline Asian or Pacific Islander & $(1.6)$ & $(1.2)$ & \\
\hline Unknown & $(17.8)$ & $(4.0)$ & \\
\hline Pre-diabetes & $(0.0)$ & $(0.3)$ & \\
\hline Diabetes type & & & 0.247 \\
\hline Type 1 & $(3.4)$ & $(5.6)$ & \\
\hline Type 2 & $310 \quad(96.6)$ & $302 \quad(94.1)$ & \\
\hline Hypertension diagnosis ${ }^{b}$ & $256 \quad(79.8)$ & $269 \quad(83.8)$ & 0.183 \\
\hline Smokers $^{c}$ & $45 \quad(14.0)$ & $(9.3)$ & 0.065 \\
\hline \multicolumn{4}{|c|}{$\begin{array}{l}\text { aP values for age were determined by individual sample t-tests; P values for race, } \\
\text { diabetes, hypertension, and smokers were determined by cross-tabulations with chi } \\
\text { square analysis; missing values for race were excluded. } \\
\text { bHypertension defined by International Classification of Diseases, Ninth Revision, } \\
\text { Clinical Modification (ICD-9-CM) codes 401.0-401.9. } \\
\text { 'Baseline count of patients who smoke. } \\
\text { SD=standard deviation. }\end{array}$} \\
\hline
\end{tabular}

microalbumin assessment, annual dilated eye exam, annual foot exam, SMBG performed at least once daily, and dietician visits in the last 12 months (Table 2). The usual care group had a higher proportion of patients with Alc $<7 \%$ (71.0\% vs. $50.8 \%, P<0.001$ ) and a lower proportion with no leisure time physical activity $(19.3 \%$ vs. $38.6 \%, P<0.001)$. The usual care group failed to achieve the target goals for formal education, annual eye and foot exam, annual dietician visit, and total smoker goals; smoking cessation counseling was provided to more than $75 \%$ of smokers in both the usual care $(77.8 \%$, $\mathrm{n}=35 / 45)$ and intervention groups $(76.7 \%, \mathrm{n}=23 / 30)$. Some initiatives or goals, such as documentation of dental exams, were not measurable or easily retrievable through data queries or medical chart review and thus were modified or omitted from the study.

With regard to the HP2010 objective for chronic kidney disease, both the intervention and usual care groups far exceeded the 30\% target for use of angiotensin-converting enzyme (ACE) inhibitors or angiotensin II receptor blockers (ARBs) in patients with proteinuria, and there was no difference between the intervention group and usual care. Neither group met the 75\% target for dietician visits in the past year, but the intervention group had a higher proportion of patients who had a visit with a dietician $(48.9 \%$ vs. $7.5 \%, P<0.001)$.

\section{TABLE 2 Attainment of ADA/Healthy People 2010 Objectives}

\begin{tabular}{|c|c|c|c|c|c|c|}
\hline Objectives & Goal/Target & Usual Ca & Ire $(n=321)$ & Intervent & ion $(n=321)$ & $P$ Value ${ }^{\mathrm{a}}$ \\
\hline BP goalb & $<130 / 80 \mathrm{~mm} \mathrm{Hg}(\mathrm{ADA}) \mathrm{c}$ & $48.0 \%$ & $(123 / 256)$ & $44.6 \%$ & $(120 / 269)$ & 0.430 \\
\hline LDL-C goal & $<100 \mathrm{mg}$ per $\mathrm{dL}(\mathrm{ADA})^{\mathrm{c}}$ & $59.2 \%$ & $(190)$ & $76.0 \%$ & $(244)$ & $<0.001$ \\
\hline Alc goal & $<7 \%(\mathrm{ADA}) \mathrm{c}$ & $71.0 \%$ & (228) & $50.8 \%$ & (163) & $<0.001$ \\
\hline Documented Alc in last 6 months ${ }^{\mathrm{d}}$ & $\geq 72 \%(\mathrm{HP} 2010)$ & $99.7 \%$ & $(320)$ & $100.0 \%$ & $(321)$ & 0.317 \\
\hline Received formal diabetes education & $\geq 60 \%$ (HP2010) & $40.2 \%$ & (129) & $93.4 \%$ & $(300)$ & $<0.001$ \\
\hline Documented annual urinary microalbumin & $\geq 14 \%(\mathrm{HP} 2010)$ & $85.7 \%$ & $(275)$ & $92.5 \%$ & $(297)$ & 0.005 \\
\hline Documented annual dilated eye exam & $\geq 76 \%(\mathrm{HP} 2010)$ & $51.4 \%$ & $(165)$ & $84.1 \%$ & $(270)$ & $<0.001$ \\
\hline Documented annual foot exam & $\geq 91 \%$ (HP2010) & $48.9 \%$ & (157) & $80.7 \%$ & (259) & $<0.001$ \\
\hline Take an aspirin at least 15 times per month & $\geq 30 \%(\mathrm{HP} 2010)$ & $42.4 \%$ & $(136)$ & $87.2 \%$ & $(280)$ & $<0.001$ \\
\hline Perform SMBG at least once daily & $\geq 60 \%$ (HP2010) & $59.8 \%$ & $(192)$ & $98.4 \%$ & $(316)$ & $<0.001$ \\
\hline With proteinuria receiving an ACE inhibitor or ARBd,e & $\geq 30 \%(\mathrm{HP} 2010)$ & $94.5 \%$ & $(70 / 74)$ & $96.1 \%$ & $(101 / 105)$ & 0.610 \\
\hline Dietician visit(s) in last 12 months $^{\mathrm{d}}$ & $\geq 75 \%(\mathrm{HP} 2010)$ & $7.5 \%$ & $(24)$ & $48.9 \%$ & $(157)$ & $<0.001$ \\
\hline Engage in no leisure-time physical activity & $\leq 20 \%(\mathrm{HP} 2010)$ & $19.3 \%$ & $(62)$ & $38.6 \%$ & $(124)$ & $<0.001$ \\
\hline Smokers at baseline & $\leq 12 \%(\mathrm{HP} 2010)$ & $14.0 \%$ & $(45)$ & $9.3 \%$ & $(30)$ & 0.065 \\
\hline Smokers who were provided cessation counselingf & $\geq 75 \%(\mathrm{HP} 2010)$ & $77.8 \%$ & $(35 / 45)$ & $76.7 \%$ & $(23 / 30)$ & 0.910 \\
\hline
\end{tabular}

ap values calculated using chi-square analysis.

${ }^{b}$ Denominator is the count of patients with hypertension at baseline.

${ }^{c} A l c, L D L$, and BP goals according to ADA recommendations (there are no target values for these measures). All other objects are goals/modified goals according to HP2010 objectives. 12

dDenotes modified goal.

eDenominator is the count of patients with albuminuria at baseline.

fDenominator is the count of patients who smoked at baseline.

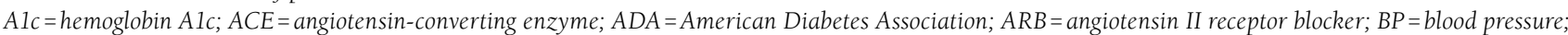

HP2010 = Healthy People 2010 initiative; LDL-C=low-density lipoprotein cholesterol; $m g$ per dL=milligrams per deciliter; mm Hg=millimeters mercury; SMBG=selfmonitored blood glucose. 


\begin{tabular}{|c|c|c|c|c|c|c|c|c|}
\hline \multirow{4}{*}{$\begin{array}{l}\text { Influenza vaccination }-\mathrm{n}(\%) \\
\text { Pneumococcal vaccination }-\mathrm{n}(\%) \\
\end{array}$} & \multicolumn{4}{|c|}{ Aged $<65$ Years } & \multicolumn{4}{|c|}{ Aged $\geq 65$ Years } \\
\hline & Target $^{\mathrm{a}}$ & $\begin{array}{c}\text { Usual Care } \\
\mathbf{n}=159\end{array}$ & $\begin{array}{c}\text { Intervention } \\
\mathrm{n}=185\end{array}$ & $P$ Value $^{\mathrm{a}}$ & Target $^{\mathrm{a}}$ & $\begin{array}{c}\text { Usual Care } \\
n=162\end{array}$ & $\begin{array}{c}\text { Intervention } \\
\mathbf{n}=136\end{array}$ & $P$ Value $^{\mathrm{b}}$ \\
\hline & \multirow{2}{*}{$\begin{array}{c}\geq 60 \% \\
(\mathrm{HP} 2010)\end{array}$} & $44 \quad(27.7)$ & $83 \quad(44.9)$ & 0.001 & \multirow{2}{*}{$\begin{array}{c}\geq 90 \% \\
\text { (HP2010) }\end{array}$} & $108(66.7)$ & $99(72.8)$ & 0.501 \\
\hline & & $38 \quad(23.9)$ & 72 (38.9) & $<0.001$ & & $74 \quad(45.7)$ & 99 (72.8) & $<0.001$ \\
\hline $\begin{array}{l}\text { aThe targets were unchanged in the He } \\
\text { bP value calculated using chi square an } \\
\text { HP2010= Healthy People } 2010 \text { initiati }\end{array}$ & People 20 & jectives. ${ }^{12,13}$ & & & & & & \\
\hline
\end{tabular}

\section{Discussion}

Clinical pharmacists are gaining increasing roles in the management of diabetes. ${ }^{14-16}$ The results of the present study support the role of the pharmacist in helping diabetes patients meet the ADA (2009) and HP2010-2020 preventive care objectives. Pharmacists in collaborative practice in diabetes management in medical groups may support primary care physicians and other clinicians in meeting preventive care objectives. The results of the present study have been used by this medical group to help validate the value of pharmacists in the delivery of care to patients with diabetes and as a model for the management of other chronic diseases. The organization uses these results to help promote the value of the pharmacist-managed diabetes clinic to PCPs. In addition, many of the HP2010 objectives evaluated in this study are core measures of pay-for-performance programs in which the medical group participates. The role of pharmacist involvement in diabetes management is further solidified by these results as they directly impact organizational goal attainment for these pay-for-performance measures. Lastly, the results of this study have helped highlight the need for processes to assist PCPs in identifying which preventive care services are needed for a given patient. Thus, pharmacists can assist physicians and other clinicians in helping patients achieve diabetes preventive measures, which may ultimately decrease complications, reduce costs, and increase quality of life.

Although the proportion of patients achieving the target for average Alc was higher in the usual care group and leisuretime physical activity was more common among patients in the usual care group, physicians in this medical group often refer patients who are uncontrolled and need significant improvement to the pharmacist-managed diabetes clinic. Pharmacists may also enroll patients in the pharmacist-managed diabetes clinic under protocol, without specific physician referral, when Alc is $9 \%$ or greater.

\section{Limitations}

The foremost limitation of this study was the inability to assess clinical care improvement because of the absence of baseline values. Second, our use of an observational design without random assignment to the intervention and usual care groups prevented attribution of causality. Third, at the time this study was conducted, patient data were retrospectively collected from 2007 and analyzed using the 2009 ADA recommendations. The ADA guidelines for aspirin therapy changed in 2010 in which aspirin is no longer recommended in every diabetes patient over 40 years of age..$^{10}$ Additionally, this study compares results with goals from the HP2010 initiative, which was superseded by HP2020 that includes other new and modified objectives for diabetes, such as improving glycemic control, blood pressure, and lipids among the population diagnosed with diabetes, as well as increasing the proportion of people at risk for diabetes who are engaged in behaviors to prevent diabetes. Objectives that were retained from HP2010, but modified include reducing the annual number of new cases of diagnosed diabetes and reducing the death rate among those with diabetes.

Fourth, lack of complete and/or adequate documentation in the EMRs was a limitation in terms of the statistical analysis. For example, evaluation of services such as eye exams and dental exams are only included in the medical record if the treating ophthalmologist, optometrist, or dentist copies the PCP on their documentation. It is not standard practice for dentists and optometrists to report patient visits back to the medical center. Fifth, both physical activity and smoking cessation attempts were self-reported and therefore may not be reliable. Sixth, this study examined patient data from mostly elderly Caucasians who have health insurance; therefore, this group may not be representative of patients in other settings.

\section{Conclusions}

Adults with diabetes who had at least 2 visits to the pharmacist-managed diabetes clinic in 2007 attained 9 of 14 Healthy People 2010 objectives compared with 7 of 14 objectives attained by patients in usual care managed by PCPs and other clinicians without clinical pharmacist involvement. The absence of baseline values for Alc, blood pressure, and LDL-C prevented longitudinal assessment of the effects of this clinical pharmacist intervention. 


\section{Clinical Pharmacist Intervention and the Proportion of Diabetes Patients Attaining Prevention Objectives in a Multispecialty Medical Group}

\section{Authors}

ROSALYN S. PADIYARA, PharmD, CDE, is Associate Professor; and JENNIFER J. D'SOUZA, PharmD, CDE, is Associate Professor, Department of Pharmacy Practice, Midwestern University College of Pharmacy, Downers Grove, Illinois. RAMI S. RIHANI, PharmD, is Director of Pharmacy Services and Chronic Disease Management; and ROSALYN S. PADIYARA and JENNIFER J. D'SOUZA, are Clinical Pharmacists, Dreyer Medical Clinic, Aurora, Illinois.

AUTHOR CORRESPONDENCE: Rosalyn S. Padiyara, PharmD, CDE, Associate Professor, Midwestern University Chicago College of Pharmacy, 555 31st St., Downers Grove, IL 60515-1235. Tel.: 630.515.6261; Fax: 630.515.6958; E-mail: rpadiy@midwestern.edu.

\section{DISCLOSURES}

This study was not funded, and the authors report no financial or other conflicts of interest related to the subject of this article. Interim study results were presented as a poster abstract at the American Society of Health-System Pharmacists Midyear Meeting, December 8, 2008, in Orlando, Florida.

Padiyara conceived and designed the study, collected and interpreted the data, and wrote and revised the manuscript, with the assistance of D'Souza and Rihani.

\section{ACKNOWLEDGEMENTS}

The authors would like to thank Hope Juska, PharmD, for her assistance with data collection and Thomas Reutzel, PhD, and Meghana Aruru, PhD, for their assistance with statistical analysis.

\section{REFERENCES}

1. Al-Mazroui NR, Kamal MM, Ghabash NM, Yacout TA, Kole PL, McElnay JC. Influence of pharmaceutical care on health outcomes in patients with type 2 diabetes mellitus. Br J Clin Pharmacol. 2009;67(5):547-57. Available at: http://www.ncbi.nlm.nih.gov/pmc/articles/PMC2686072/pdf/bcp0067-0547. pdf. Accessed June 17, 2011.

2. Clifford RM, Davis WA, Batty KT, David TME. Effect of a pharmaceutical care program on vascular risk factors in type 2 diabetes: the Fremantle Diabetes Study. Diabetes Care. 2005;28(4):771-76. Available at: http://care. diabetesjournals.org/content/28/4/771.full.pdf+html. Accessed June 17, 2011.

3. Krass I, Armour CL, Mitchell B, et al. The Pharmacy Diabetes Care Program: assessment of a community pharmacy diabetes service model in Australia. Diabet Med. 2007;24(6):677-83.
4. Jameson JP, Baty PJ. Pharmacist collaborative management of poorly controlled diabetes mellitus: a randomized controlled trial. Am J Manag Care. 2010;16(4):250-55. Available at: http://www.ajmc.com/media/pdf/ AJMC_10apr_Jameson_250to255.pdf. Accessed June 17, 2011.

5. Simpson SH, Johnson JA, Biggs RS, Tsuyuki RT; SCRIP Investigators. Greater effect of enhanced pharmacist care on cholesterol management in patients with diabetes mellitus: a planned subgroup analysis of the Study of Cardiovascular Risk Intervention by Pharmacists (SCRIP). Pharmacotherapy. 2004;24(3):389-94.

6. Planas LG, Crosby KM, Mitchell KD, Farmer KC. Evaluation of a hypertension medication therapy management program in patients with diabetes. J Am Pharm Assoc (2003). 2009;49(2):164-70.

7. American Diabetes Association. Standards of medical care in diabetes-2009. Diabetes Care. 2009;32(Suppl 1):S13-61. Available at: http://care. diabetesjournals.org/content/32/Supplement_1/S13.full. Accessed June 18, 2011.

8. American Diabetes Association. Diabetes basics. Diabetes statistics. Data from the 2011 National Diabetes Fact Sheet (released January 26, 2011). Available at: http://www.diabetes.org/diabetes-basics/diabetes-statistics/. Accessed June 17, 2011.

9. American Diabetes Association. Standards of medical care in diabetes-2010. Diabetes Care. 2010;33(Suppl 1):S11-61. Available at: http://care. diabetesjournals.org/content/33/Supplement_1/S11.full. Accessed June 18, 2011

10. American Diabetes Association. Standards of medical care in diabetes-2011. Diabetes Care. 2011;34(Suppl 1):S11-61. Available at: http://care. diabetesjournals.org/content/34/Supplement_1/S11.full. Accessed June 18, 2011

11. Centers for Disease Control and Prevention. Vaccines and immunizations: recommendations and guidelines. January 31, 2011. Available at: http://www.cdc.gov/vaccines/recs/. Accessed June 17, 2011.

12. HealthyPeople.gov. Healthy People 2010: volume I (second edition) and volume II (second edition). Available at: http://www.healthypeople.gov/2010/ Publications/. Accessed June 17, 2011.

13. HealthyPeople.gov. Healthy People 2020: summary of objectives. Diabetes. June 14, 2011. Available at: http://healthypeople.gov/2020/topicsobjectives2020/objectiveslist.aspx?topicid=8. Accessed June 17, 2011 .

14. Scott DM, Boyd ST, Stephan M, Augustine SC, Reardon TP. Outcomes of pharmacist-managed diabetes care services in a community health center. Am J Health Syst Pharm. 2006;63(21):2116-22.

15. Fera T, Bluml BM, Ellis WM, Schaller CW, Garrett DG. The Diabetes Ten City Challenge: interim clinical and humanistic outcomes of a multisite community pharmacy diabetes care program. J Am Pharm Assoc (2003). 2008;48(2):181-90

16. Cranor CW, Bunting BA, Christensen DB. The Asheville Project: longterm clinical and economic outcomes of a community pharmacy diabetes care program. J Am Pharm Assoc (Wash). 2003;43(2):173-84.

17. HealthyPeople.gov. History and development of Healthy People. Available at: http://healthypeople.gov/2020/about/history.aspx. June 1, 2011. Accessed June 17, 2011 